\title{
3 Caring masculinity: Fathers' childcare in Japan and Norway
}

\author{
Masako Ishii-Kuntz
}

\section{Fatherhood: A brief history}

This chapter examines fathers' involvement in childcare in Japan and Norway since the 1990s, a pivotal decade marked by major policy changes in parental leave that have had far-reaching consequences. After reviewing the major policies enacted from the 1990s to the present, we will examine how they may have affected fathers' involvement in childcare by reviewing publicly available statistics relating to parental leave. Second, looking closer at what factors may be related to the levels of fathers' childcare participation, we consider a range of social and ideological factors predicting paternal involvement. We will do this by constructing and examining a model by a multi-sample structural equation analysis. In particular, this model looks at how intersectional dimensions, such as employment status, education and age, predict men's gender ideology, which, in turn, influences men's childcare involvement. What insights does the model provide into explaining the extent of fathers' childcare within and across both national contexts? How are some factors differentially affecting fathers' childcare involvement in both countries? These are some of the questions to be addressed by the statistical analyses of the data collected in Japan and Norway in 2020 .

The historical review of modern Norwegian fatherhood is typically divided into three main periods in which notable changes in the position of fatherhood occurred (Lorentzen, 2013). The first period of 1850-1927 is represented by fathers in farming business. During this period of premodernisation, the sharing of work and household responsibilities between mothers and fathers was common (Lorentzen, 2013). A shift to industrialisation and urbanisation in 1927-1970, however, positioned fathers as the main economic providers. In the third period of 1970-2012, fathers again became very involved in childcare. This coincides with 'women's entry into the workplace, women's demand for equality' (Lorentzen, 2013, p. 110) which may have contributed to the collapse of the gendered division of household labour. In 1985, a national Commission on the Role of Men was formed to discuss the subject of men and gender equality. In 1991, the

DOI: $10.4324 / 9781003185222-3$ 
Commission issued its final report entitled 'Men and Care' which emphasised, among other things, the importance of mothers and fathers having equal entitlement to parental leave. It recommended instituting a 'father's quota,' whereby fathers would receive four-weeks paid parental leave, and if they did not take this leave, they would lose that much childcare leave time. The Commission gave three reasons for recommending the father's quota: The need to ensure equality between fathers and mothers, fathers' needs to care for their children and the children's needs for more contact with their fathers. In 1993, the father's quota was formally established in the new national parental leave policy.

In Japan, too, industrialisation and urbanisation affected the role of fathers. Although a few studies report that Japanese fathers were involved in educating and disciplining their sons in Edo period (1603-1868) (Ohta, 1994), childrearing became naturalised as the primary task of mothers throughout the Industrialisation Era. As in Norway, urbanised post-war Japanese society positioned fathers as breadwinners outside the home and mothers as primary caregivers within the home. It was not until the 1990s that the Japanese began paying more attention to fathers' roles and diverse types of fatherhood (Ishii-Kuntz, 2013). This increasing attention can be attributed to the so-called ' 1.57 (fertility) shock' of 1989, which marked the beginning of governmental efforts to establish family-friendly laws and policies, including campaigns for increased paternal involvement, to boost the nation's birth rate. The diversity of views about fatherhood was also debated in the 1990s. On the one hand, conservative critics advocated for the strong presence of fathers as authoritarian figures, as Hayashi (1996) wrote in his book Fusei no Fukken (Restoration of Paternity). On the other hand, several books about involved fathers were written by men who took childcare leave, and who went on daily one-hour 'strikes' to take their children to day-care centres (Otoko mo onna mo ikuji jikan o renrakukai, 1995; Tajiri, 1990). A confluence of factors contributed to the increasing attention to fatherhood in the 1990s: The decline in fertility and the subsequent government campaigns promoting paternal involvement, fatherhood research in developmental psychology, the introduction of men and masculinity studies to Japanese academia and general public, research on mothers' childcare stress and anxiety in family sociology, and the emergence of men's and fatherhood movements.

\section{Parental leave policy}

\section{Norway: The father's quota}

Today, Norwegian family policy is widely known for its generosity and for its significant role in supporting both high female labour-force participation and men's involvement in childcare. Although the state provision for childcare remained incomplete well into the 1980s, the introduction of the 
father's quota in the 1993 parental leave policy certainly enhanced Norway's journey to gender equality in the area of domestic chores.

Essentially, the father's quota system gave Norwegian fathers four weeks of 'use-it-or-lose-it' parental leave. Before the introduction of this system, only about $3 \%$ of men took paternity leave. Initially, Norway's rationale for establishing fathers' childcare leave and the quota system was to promote gender equality, a response to the agenda taken up by the strong women's movement in the beginning of the 1990s. Scholars such as Sainsbury (1996) would suggest that the paternity leave can be seen as breaking the male breadwinner model as well as granting father's individual right, but the parental leave and the quota system in Norway are not exactly based on an ideology of individual rights.

Despite the ideological battle over gender equality and individual rights discourse surrounding the father's quota over the last two decades, the research analysing the effects of paternity leave in Norway has focused mainly on the father-child relationship. Stated another way, today, the discussion of the father's quota is less about ensuring gender equality in the home, and more about the importance of father-child bonding. This research underscores the benefits to children and society when men participate more equally in caregiving work. Brandth and Kvande (2003), for example, described this shift in views of paternal involvement as moving away from gender equality discourse to celebrations of the nurturing fathers' positive effects on children.

Although Norway was the first country to introduce the father's quota in 1993, Sweden followed suit with a 'daddy month' in 1994. However, in both Norway and Sweden, further expansions of the father's quotas have been rather slow to occur. In fact, it has taken more than two decades to achieve quotas of about three months in both countries. Additionally, the Norwegian's father's quota policy has been contested by both the political left and right (Ellingsæter, 2020). These disagreements from both sides are perhaps due to the fact that the father's quota limits parental choice and punishes parents who do not use it.

While the 1993 quota rapidly increased fathers' use of the leave, few fathers took more than the four weeks, allowing mothers to take most of the shareable part of the leave. With the pressure to increase the father's quota, the government initiated the first extension, which led to the addition of one week to the total leave in 2005. Since 2005, the total parental leave has been extended from 42 to 49 weeks with $100 \%$ compensation from the workplace. In a move that recognised the importance of father's involvement in parenting, three weeks were transferred from the sharable part of the leave to the father's quota. Reverberations from the global financial crisis of 2008, however, changed attitudes toward the father's quota dramatically. In 2010, the Conservative Party joined the Progress Party in its goal to abandon the father's quota altogether. Although these parties 
worked to abolish the quota, the Christian Democratic Party and the Liberal Party later negotiated a compromise that allowed the quota to remain, but reduced it. As a result, in 2014 the quota dwindled from 14 to 10 weeks.

In 2017 , a parliamentary majority was in favour of reversing the cut to the father's quota in an effort to give children more time to spend with their fathers and to contribute to gender equality in the workplace (Ellingsæter, 2020). This majority successfully requested the re-elected minority rightwing government to present a bill restoring the father quota to the previous 14 weeks. Under Norway's current policy, effective as of July 2018, mothers get 15 weeks of non-transferable leave, plus three weeks before birth. It once again became popular for fathers to take parental leave. The importance of the parental leave system, including a special quota for fathers, is regarded positively today. Research has shown how a statutory, earmarked and non-transferable leave has impacted on the high use of the leave by Norwegian fathers (Brandth \& Kvande, 2020). This may mean that men's use of parental leave may be due to the nature of the way the leave is structured rather than the benefits to fathers and children.

\section{Japan: Revisions in parental leave policy}

In 1999, the Basic Act for Gender-Equal Society was enacted by the Japanese government. This Act includes the basic principles to form a gender-equal society and lays out the respective duties of the state, local governments and citizens. Additionally, it clearly states that both women and men are equal participants in labour force and family care. In 2000, the second phase of Basic Plan for a Gender-Equal Society was released to further promote gender equality in Japan. Then the third phase emphasised the importance of changing men's lives with an emphasis on reducing their long work hours and increasing their childcare involvement. In the fourth phase, however, plans directly related to men's involvement in childcare and elder care seem to have been significantly reduced perhaps due to a more conservative turn with the ruling Liberal Democratic Party in the Japanese Parliament. This pattern continued in the most recent fifth phase of the plan which was released in December 2020.

Much of the impetus for promoting men's caregiving comes from the ongoing crisis of Japan's low fertility rate. The Japanese government, with the assumption that the husbands' participation in childcare would encourage women to have more babies, revised the Childcare Leave Law in 1992 allowing fathers, for the first time, to take parental leave from work. However, there was no state compensation stipulated for such leave as it has been in Norway. It was not until one year later, in 1993, that Norway introduced the fathers' quota system, although the parental leave where fathers were allowed to share leave time with the mothers had been 
introduced in Norway in 1977. Japanese fathers' use of the parental leave was considered not only 'progressive' at the time but it was also seen difficult to actually use it due to the lack of financial compensation and health insurance coverage during the leave as well as harassment by and lack of understanding from their supervisors and co-workers (Ishii-Kuntz, 2013).

In 2010, the following three major categories were added to the Child Care and Family Care Leave Law:

1 Men whose wives are full-time homemakers can take the parental leave. (Prior to this, only men whose wives were employed could use the leave.)

2 If fathers take the first parental leave during their wives' maternity leave, they can take the leave again after the maternity leave ends. (Prior to this, men could take the leave only once during the 12-months after the birth of the baby but now they can take two leaves of equal or different duration.)

3 If both fathers and mothers use parental leave, then they can extend the leave up to 14 months. This is called 'Papa Mama Childcare Plus.' (Prior to this, either the father or mother could only take up to 12 months parental leave. If fathers take the leave, then the entire parental leave can be extended to 14 months.)

Although Japan and Norway have both been promoting fathers' childcare for the past several decades, there has been a gap in the proportion of Norwegian and Japanese men taking up such a leave. The report prepared by the Japan Institute for Labour Policy and Training (2017) shows that close to $90 \%$ of Norwegian fathers today take childcare leave. Although it has been almost 30 years since the 1992 revision of the Child Care Leave Law in Japan, which allowed men to take the parental leave, the proportion of Japanese men taking advantage of such a leave remains quite low at about only $7 \%$ in 2021 .

Figure 3.1 shows the changes in women and men in Japan taking childcare leave from work between 2007 and 2019. The percentages of women taking childcare leave fluctuate between 81.5 and 87.8. In contrast, only a small proportion of Japanese men take such a leave, although the percentages increased from 1.38 in 2010 to 7.48 in 2019. Similar gender differences are also noted with respect to the length of childcare leave between mothers and fathers. As shown in Figure 3.2, 31.1\% of women take 10-12 months leave, whereas the majority of men $(56.9 \%)$ are taking a leave of less than five days, despite the Papa Mama Childcare Plus initiative.

\section{Norway and Japan: Moving closer?}

Is Japan's family policy moving closer to the Nordic model of childcare schemes? Japanese lawmakers often praise the Norwegian model of 


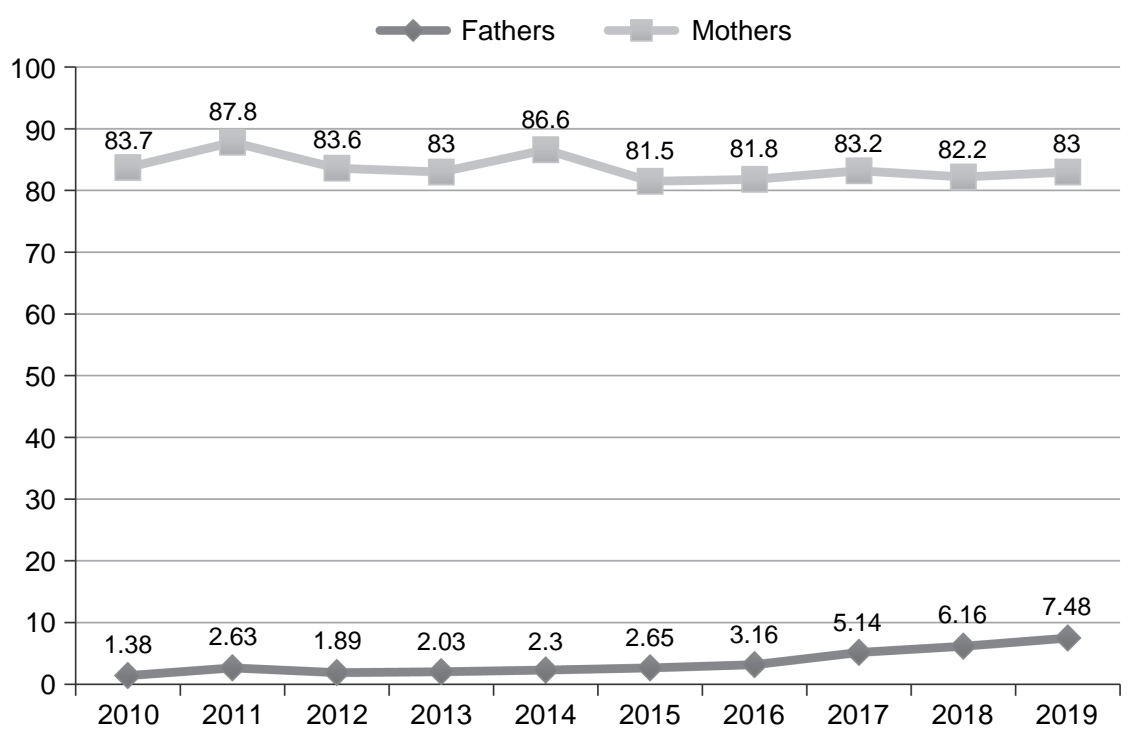

Figure 3.1 Percentage of mothers and fathers taking parental leave in Japan, 2010-2020.

Source: Adapted from Ministry of Health, Labour and Welfare, 2020, figure compiled by the author.

parental leave policy. In fact, the topic of father's quota in parental leave policy has been debated in the Japanese political arena. Atoh and Akachi (2005) suggested that there may be a possibility that Nordic family policy measures such as the father's quota could have an equalising effect on gender relations and hence result in better work-family harmonisation in Japan.

Japanese family policy has ostensibly moved closer to the Norwegian model over the 1990s and early 2000s. However, regardless of Japan's admiration of the parental leave policy in Norway, the relevant services are hardly guaranteed to all Japanese as a matter of right since only full-time regular employees are eligible for parental leave, whereas in Norway, parttime workers are also eligible to take the leave. Also, Toivonen (2007) argued that the Japanese childcare and parental leave schemes are weak in terms of continuity when compared to Nordic equivalents. While the new parental leave scheme of 2010 such as Papa and Mama Childcare Plus resembles the fathers' quota system on surface, the stringent eligibility conditions together with women's weak labour market position reduce this similarity in practice. For the latter, it is the gendered wage gap that makes it difficult for men to take up the leave because it means a large income loss in the family. Furthermore, regarding the context for the development of 


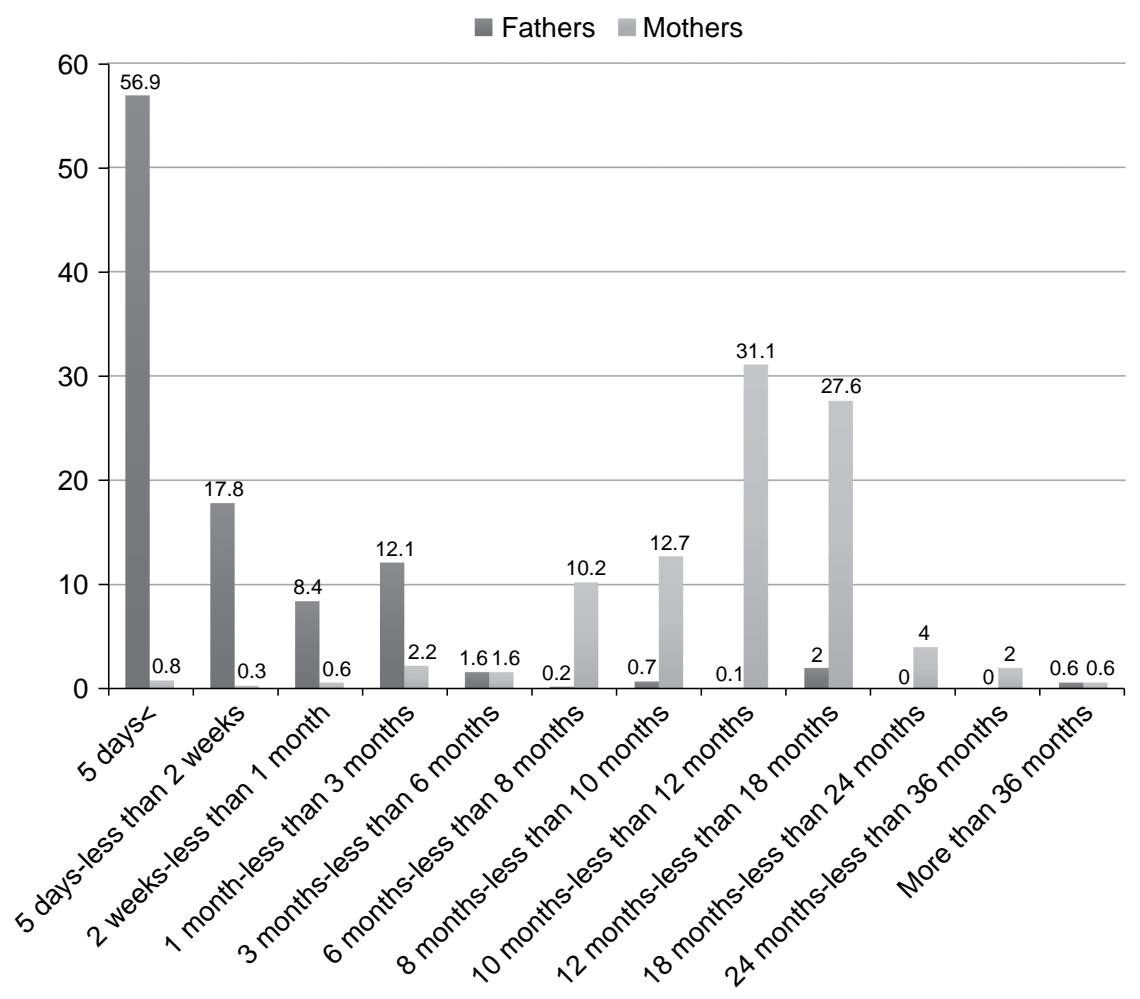

Figure 3.2 Duration of parental leave for mothers and fathers in Japan.

Source: Adapted from Ministry of Health, Labour and Welfare, 2020, figure compiled by the author.

more generous family policies, a lack of continuity in welfare discourse, the comparatively weak political influence of women and the heavy economic burdens associated with demographic ageing in Japan are factors that have constrained (and are likely to continue to constrain) the development of such policies in Japan. In addition, hegemonic masculinity is still firmly in place in Japan which gives little encouragement to any men who wishes to give priority to childcare.

Today, the debate over fathers' childcare leave continues in both countries. In Japan, for example, the head of the Ministry of the Environment declared in 2019 to take merely two weeks of parental leave but he was criticised by his fellow politicians, because they thought that the public servants should not take the leave from work for personal reasons. In Norway, the debate over abolishing the father's quota system is still alive because some argue that it is not fair that mothers and fathers are not entitled to the same length of the parental leave (Ellingsæter, 2020). 


\section{Fathers' childcare: Data comparisons}

Here, we will look at the publicly available data to compare the extent of fathers' involvement in childcare in both countries. According to the 2016 Japan's Gender Equality Bureau's comparison between Norway and Japan concerning men and women's involvement in housework and childcare, Japanese husbands spend approximately 1.23 hours/day for household labour, which includes 0.49 hours of childcare activities. The comparable figures for Norwegian fathers are 3.12 hours for household labour out of which 1.13 hours are spent for childcare activities. This comparison generates the finding that Norwegian fathers are 2.5 times more likely than their Japanese counterparts to be involved in household labour including childcare. For Japanese mothers, 7.34 hours/day are devoted to household labour with 3.45 hours used for childcare. Norwegian mothers spend 5.26 hours in household labour, which includes 2.17 hours of childcare. Although Japanese mothers spend longer time in housework and childcare than do Norwegian mothers, the gendered pattern of the division of household labour in which mothers are more likely to be engaged can be seen from these figures.

These statistics make it clear that Norwegian men are much more likely to be involved in childcare compared to their Japanese counterparts. We need to be aware that this does not assume that gender equality in childcare has completely been achieved in Norway, since mothers are still the default caretakers of their children (Ringrose, 2017; Sørensen, 2017). Additionally, mothers' and fathers' childcare participation may be different depending on the content of care. It is also important to note that fathers' childcare involvement may be different between Japan and Norway because of the differences of the daily life customs in both countries. These possibilities will be described in the following section with the data collected in both countries. Given that gender disparity in childcare involvement still exists in Japan and Norway, it is worth investigating how different factors are affecting men's childcare involvement in the two contexts.

\section{Factors predicting the levels of fathers' childcare}

We begin this section by reviewing the previous literature on factors affecting fathers' involvement in childcare in order to generate the analytical model shown in Figure 3.3. In this model, the hypotheses tested in the prior literature, such as relative resources and childcare demand, will be included along with new factors, such as men's attitudes toward gender roles at work and home.

Using quantitative data collected in the spring of 2020 in Japan and Norway, we will test this analytical model to directly compare the predictors of fathers' childcare in both countries. In other words, Japanese and Norwegian data are compared by a multi-sample structural equation model 


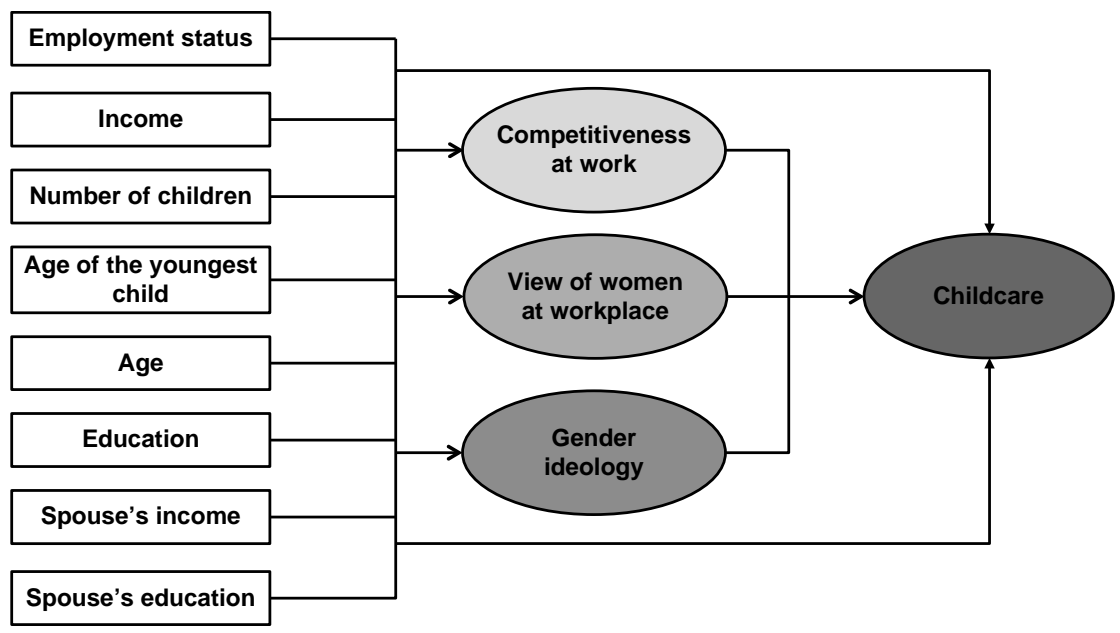

Figure 3.3 Analytical model predicting fathers' childcare involvement.

Source: Figure created by the author.

that analyses the same model using two samples, one from Japan and the other from Norway. This analysis allows the direct comparison of the estimated parameters for both countries.

\section{Antecedents to fathers' childcare}

Prior studies (Ishii-Kuntz, 2009, 2013) examined relative resources, time availability, gender ideology and childcare demands, among others, as predictors of fathers' participation in childcare. According to Relative Resources Hypothesis, husbands with more resources, such as income and educational background, than those of their wives are less likely to be involved in childcare. As for time availability, husbands who spend more time at home than those who spend less time are predicted to perform more childcare duties. Gender Ideology Hypothesis posits that husbands who hold liberal attitudes toward gender roles would be frequently involved in childcare. Childcare demands are higher when there are more children and younger children in the household, and if so, fathers are more likely to participate in childcare. Additionally, Ishii-Kuntz (2013) found that fatherfriendly practices at work and the existence of role models are positively related to men's taking childcare leave.

In our analysis, we will examine the effects of fathers' employment status, income, age, education, as well as their spouse's income and education (as indicators of the spouse's resources), and number and age of children (as indicators of childcare demands) to examine how these variables are related to fathers' childcare. We also include gender ideology as an intervening variable. 
Another dimension examined in our study is the relationship between masculinity measures and men's childcare involvement. For many years, Japanese men have been characterised by hegemonic masculinity, which emphasises the importance of their breadwinning role. As previously mentioned, in recent years, however, we have been witnessing the rise of men who are active participants in care work, including housework and childcare.

There has also been a growing theoretical and research interest in what is considered as a new form of masculinity, known as a caring masculinity, which is a masculine identity that rejects domination and embraces values of care, such as interdependence and relationality (e.g., Elliott, 2015). Although caring masculinity became a focus of many European critical studies of men and masculinity, it has never been extensively studied within Asian contexts.

Based on the explanation above, we will analyse the following model using the comparative data collected in Norway and Japan. We predict that fathers with full-time employment and higher educational attainment, who earn higher income, have fewer children, whose children are older and whose spouses' income and educational levels are lower, are less likely to be involved in childcare. In addition, these variables are predicted to influence such intervening variables as men's competitiveness at work, views toward their female co-workers and bosses, and gender ideology, which, in turn, influence their childcare involvement. Stated another way, men who are competitive at work, hold conservative views and attitudes toward their female co-workers or bosses and have traditional ideology toward gender roles are less likely to be involved in childcare. For the sake of the direct crosscultural comparison, we will analyse the same model for Norway and Japan.

\section{Methods and sample characteristics}

The data used in this research come from an ongoing cross-cultural project on men and masculinities sponsored by the Sasakawa Peace Foundation in Tokyo. The data were collected by a web survey in the spring of 2020 from married men aged 20-69 who have at least one child and were residing in Norway $(\mathrm{n}=114)$ and Tokyo $(\mathrm{n}=332)$. Initially, we aimed to collect data from the capital cities in both countries. However, given the scarcity of the Norwegian population, we needed to go beyond Oslo to collect enough data for our analysis. Thus, the Norwegian data were collected nationwide, whereas the Japanese data were collected from those living in Tokyo.

Our sample has some demographic differences among the Japanese and Norwegian men, although they are not nationally representative samples. The average age of Japanese fathers is 41.2 , about ten years younger than the Norwegian fathers (51.1). Approximately $62.9 \%$ and $50.2 \%$ of Japanese and Norwegian men, respectively, are college educated. The majority $(84.4 \%)$ of Japanese men are employed and the comparable figure for Norwegian men was 
$61.7 \%$. Dividing these men's incomes into five categories (high, somewhat high, middle, somewhat low, low), we found that $31.9 \%$ of Japanese and $50.2 \%$ of Norwegian men belong to 'high' or 'somewhat high' brackets. With respect to differences in income between husbands and wives, there is a significantly larger gap in Japan (almost 3 million yen, or 254,000 NOK) compared to that of Norwegian couples $(39,587$ yen, or 3360 NOK).

\section{Measurements}

To identify employment status, respondents were asked whether they currently are employed, employed but taking a leave or not employed. Their annual income was measured by categories ranging from 'none' to 'over 500,001 kroner' for Norwegian fathers and from 'none' to 'more than $23,000,000$ yen' for Japanese fathers. With respect to their educational attainment, they were asked to state the last school they attended. Spouse's income and education were similarly measured.

We included three questions to measure the respondents' competitiveness at work: 'I want to increase my achievement at work to receive higher evaluations,' 'I want to win the competition at work,' and 'Men are selfconscious about their status.' Responses ranging from Not at all to Very much so for these questions were added to create a scale of competitiveness. The higher score of this scale indicates men's more competitive attitudes. Cronbach's alpha is a measure of how closely a set of question items are related with the higher scores indicating greater scale reliability. These alphas were 0.809 and 0.653 for Japanese and Norwegian data, respectively. Although the alpha for the Norway sample is lower than that of the Japanese sample, we will use this scale in our analysis because we think that the questions are quite legitimate indicators of the competitiveness.

The gender ideology scale was constructed by adding the five variables: 'Men should work outside and women should care for the family,' 'Men should provide financial resources for the family,' 'Mothers need to concentrate on childcare when their child is under the age of three,' 'It is better for a woman to do housework and childcare,' and 'It is better that women care for the elderly family member.' Again, the responses to these five questions are added to create a scale of gender ideology. Cronbach's alphas were 0.857 and 0.835 for Japanese and Norwegian men, respectively. Higher scores for this scale indicate more traditional attitudes toward gendered roles.

Finally, for our dependent variable, we created a scale of 'Fathers' childcare' by adding response scores for six questions: 'Take care of meals,' 'Eat with child,' 'Help child with clothes and getting ready,' 'Take a bath together,' 'Change diapers' and 'Play together.' The response scores ranging from Not at all to Almost every day were added to create the scale of men's childcare involvement. For these scales, Cronbach's alphas of 0.870 and 0.814 were obtained for Japanese and Norwegian samples, respectively. 


\section{Analyses}

The proposed model was analysed using descriptive statistics and Structural Equation Models (SEM).

\section{Findings: Descriptive statistics}

In terms of attitudinal scales, we found that Japanese men are more likely to be competitive at work (scoring 8.38 out of 12 , with 12 being the most competitive) compared to their Norwegian counterparts (7.98). Japanese men also report more conservative attitudes toward women at work (11.26 out of 20) than did Norwegian men (9.57). With respect to gender ideology, Japanese men were again found to hold more traditional gender ideology (12.93 out of 20) than did Norwegian men (9.57).

As predicted, for childcare involvement, Norwegian men were involved in childcare much more frequently than their Japanese counterparts, though not in all categories of childcare or with uniform degrees of difference. The most notable difference was found in terms of helping the child during the meals: $49.5 \%$ and $21.1 \%$ of Norwegian and Japanese fathers, respectively, reported taking care of their children at the meal time almost every day or four to five times a week. Likewise, $30.4 \%$ of Norwegian and $21.1 \%$ of Japanese fathers frequently helped their children get dressed. In contrast, Japanese fathers were found to play with $(25.6 \%)$ and bathe $(23.1 \%)$ their children more frequently than their Norwegian counterparts $(18.7 \%$ and $20.5 \%)$. The difference in playing with children may reflect the long work hours of Japanese men. Many return home late only to be able to play with their children before bedtime rather than providing physical care. Work hours in Norway are shorter compared with men in other countries, and fathers of young children in particular have reduced their work hours over the last two decades (Kitterød \& Kjeldstad, 2003). Additionally, the difference in bathing may reflect the structural difference in which the Japanese bathroom is built to accommodate several family members at the same time.

Despite these variations, we also found that the wives in both contexts are likely to be more involved in housework than their husbands; Japanese and Norwegian husbands are involved in $32.5 \%$ and $44 \%$ of the total housework, respectively. In addition, $35.4 \%$ and $53.5 \%$ of the total childcare is performed by Japanese and Norwegian fathers, respectively. This confirms the previous finding that even in Norway, wives are 'default' providers of housework and childcare.

At the bivariate level, we found that Japanese men's competitiveness at work is significantly correlated with conservative views toward women at work and adherence to more traditional gender ideology. More conservative views toward women at work were also positively correlated with more traditional gender ideology. 


\section{Findings: Structural equation model (SEM)}

Table 3.1 shows the results of SEM based on our analytical model (see Figure 3.3). Concerning the effects of independent variables on intervening variables, it was found that Japanese men with higher income are significantly more competitive at work and have more conservative views toward women at work compared to those with lower income. Among Norwegian men, too, those with higher income reported significantly more conservative attitudes toward women at work and a more traditional gender ideology than those with lower income, which is consistent with the findings of Aarseth (2020). Those fathers who have more children hold significantly more traditional views of gender ideology compared to fathers with fewer children, and this pattern was the same in Norway and Japan.

Additionally, for Japanese fathers only, having older children was associated with holding a more traditional gender ideology. In addition, younger Japanese fathers are significantly less competitive at work, have less conservative attitudes toward women at work and have a more liberal gender ideology. Finally, Japanese wives' higher income was associated with their husbands' adherence to less traditional gender ideology.

In terms of the factors affecting fathers' childcare involvement, we found that Japanese men who have younger children and whose spouse's income is higher are more likely to be involved in childcare. For Norwegian fathers, their childcare involvement was not influenced by these factors. These direct cross-cultural comparisons show that whereas several sociodemographic variables are related to attitudinal variables, factors affecting Norwegian and Japanese fathers' childcare involvement may be quite different. This is also shown by the better fit of the model for Japanese data compared to that of the Norwegian data.

\section{Conclusions}

In this chapter, we focused on paternal involvement in childcare in Norway and Japan by comparing parental leave policies and the publicly available data. We then analysed the data collected from Norwegian and Japanese fathers in the spring of 2020 to examine factors affecting their involvement in childcare.

In terms of historical shifts in fathers' involvement in childcare, we found similar changes between the two countries. That is, both Norwegian and Japanese fathers were quite involved in childcare in earlier periods but their level of involvement decreased due to industrialisation and urbanisation. After post-war images of fathers almost hit rock bottom to the point of ridiculing and even writing off fatherhood, fathers in both countries made a comeback starting in the 1990s. In terms of parental leave policies, the two countries share certain motivations such as the emphasis on fathers' childcare involvement as beneficial to children, easing mothers' stress, and ensuring gender equality in the home. 
Table 3.1 Factors Affecting Fathers' Childcare Involvement

\begin{tabular}{|c|c|c|}
\hline Variables & Japan & Norway \\
\hline Employment $\rightarrow$ Competitiveness & -0.04 & 0.08 \\
\hline Employment $\rightarrow$ View of women at work & 0.02 & -0.05 \\
\hline Employment $\rightarrow$ Gender ideology & -0.05 & -0.05 \\
\hline Income $\rightarrow$ Competitiveness & $0.10 * *$ & 0.00 \\
\hline Income $\rightarrow$ View of women at work & $-0.13 *$ & $-0.32 *$ \\
\hline Income $\rightarrow$ Gender ideology & 0.04 & $-0.33 *$ \\
\hline Number of children $\rightarrow$ Competitiveness & -0.11 & 0.02 \\
\hline $\begin{array}{l}\text { Number of children } \rightarrow \text { View of women } \\
\text { at work }\end{array}$ & 0.07 & 0.16 \\
\hline Number of children $\rightarrow$ Gender ideology & $0.19 * *$ & $0.20 *$ \\
\hline $\begin{array}{l}\text { Age of the youngest child } \rightarrow \\
\text { Competitiveness }\end{array}$ & $0.29 *$ & -0.05 \\
\hline $\begin{array}{l}\text { Age of the youngest child } \rightarrow \text { View of } \\
\text { women at work }\end{array}$ & 0.25 & -0.04 \\
\hline $\begin{array}{l}\text { Age of the youngest child } \rightarrow \text { Gender } \\
\text { ideology }\end{array}$ & $0.34 *$ & -0.25 \\
\hline Age $\rightarrow$ Competitiveness & $-0.43 * * *$ & -0.18 \\
\hline Age $\rightarrow$ View of women at work & $-0.31 *$ & -0.25 \\
\hline Age $\rightarrow$ Gender ideology & $-0.33 *$ & -0.12 \\
\hline Education $\rightarrow$ Competitiveness & 0.07 & 0.17 \\
\hline Education $\rightarrow$ View of women at work & -0.05 & -0.02 \\
\hline Education $\rightarrow$ Gender ideology & -0.05 & 0.07 \\
\hline Spouse's income $\rightarrow$ Competitiveness & -0.08 & 0.00 \\
\hline $\begin{array}{l}\text { Spouse's income } \rightarrow \text { View of women } \\
\text { at work }\end{array}$ & -0.01 & 0.11 \\
\hline Spouse's income $\rightarrow$ Gender ideology & $-0.23 * *$ & -0.02 \\
\hline Spouse's education $\rightarrow$ Competitiveness & 0.03 & 0.00 \\
\hline $\begin{array}{l}\text { Spouse's education } \rightarrow \text { View of women } \\
\text { at work }\end{array}$ & 0.09 & -0.22 \\
\hline Spouse's education $\rightarrow$ Gender ideology & -0.02 & -0.16 \\
\hline Employment $\rightarrow$ Childcare & 0.07 & -0.14 \\
\hline Income $\rightarrow$ Childcare & -0.02 & 0.13 \\
\hline Number of children $\rightarrow$ Childcare & -0.05 & -0.05 \\
\hline Age of the youngest child $\rightarrow$ Childcare & $-0.30 *$ & -0.26 \\
\hline Age $\rightarrow$ Childcare & 0.07 & -0.28 \\
\hline Education $\rightarrow$ Childcare & 0.00 & 0.03 \\
\hline Spouse's income $\rightarrow$ Childcare & $0.15 *$ & 0.13 \\
\hline Spouse's education $\rightarrow$ Childcare & 0.00 & 0.00 \\
\hline Competitiveness $\rightarrow$ Childcare & -0.01 & -0.22 \\
\hline View of women at work $\rightarrow$ Childcare & 0.07 & -0.06 \\
\hline Gender ideology $\rightarrow$ Childcare & -0.12 & -0.08 \\
\hline GFI, AGFI, RMSEA & $\begin{array}{l}0.853 \\
0.806,0.063\end{array}$ & $\begin{array}{l}0.769 \\
0.696,0.061\end{array}$ \\
\hline
\end{tabular}

Note: $" p<0.05 ; * p<0.01 ; * * p<0.001$. Table created by the author.

Despite these similar historical transitions of fatherhood and the development of family policies, Japanese men still show reluctance to take parental leave and participate in childcare. Reasons for this gap between fathers' participation in 
childcare in Japan and Norway may owe to the differences in how parental leave policy was formulated and the lack of structural support for childcare, among others. First, allowing Japanese men to take parental leave was initiated by the government's concerns over the rapid decline of the national fertility rate. Encouraging fathers' active participation in childcare was identified as one of the driving forces necessary to encourage mothers to have more children. The Japanese government still seems to believe that fathers' use of parental leave would result in couples deciding to have more babies, despite inconsistent findings. Although parental leave and the father's quota system began as 'tools' to achieve Norway's gender equality, it was shown that parental leave is more frequently associated in recent decades with the opportunity for father-child bonding.

Second, the parental leave policy in Japan and Norway have become similar after the major revisions of the Japanese law in 2010. However, the shortage of childcare facilities after the parental leave ends is creating a major obstacle to Japanese mothers who wish to return to work. In fact, the Ministry of Health, Labour and Welfare (2017) reports that more than 20,000 children have been waitlisted to be admitted to childcare centres annually since 2010 . This shortage contrasts with the recommendation of the 2005 White Paper on the National Lifestyle which emphasizes the importance of the whole society getting involved in childrearing (Cabinet Office, 2005). The White Paper also points out that the childrearing generation is faced with a burden of taxes and pension funding for the ageing population.

The Japanese public became aware of this problem when one mother's online rant caught attention in 2016. In an article entitled, Hoikuen ochita, Nihon shine!! ('Didn't Get a Slot in Day Care Centre. Drop Dead, Japan!!') (Osaki, 2016), one mother described her frustrating struggle to find a day care centre for her child. Several dozen mothers who were inspired by the blog also held a rally in front of the Diet (Parliament) building to demand an increase in the number of day care centres while other mothers began an online campaign demanding a systemic overhaul (Osaki, 2016). Despite this campaign, however, we have not seen any significant improvement surrounding mothers who wish to return to work after taking up the parental leave.

Finally, our analyses of the data collected in Norway and Japan revealed that although sociodemographic variables, such as income and number of children, seem to have similar effects on father's childcare, none of the attitudinal variables explain the extent of paternal involvement in both countries. Thus, we need to re-evaluate the analytical model while taking into account the differences in the very meaning of paternal involvement in childcare in Norway and Japan. To this end, in-depth interviews with Norwegian and Japanese fathers asking them about the meaning of fatherhood and fathers' involvement in childcare may provide insightful findings. 


\section{Acknowledgements}

The author gratefully acknowledges the use of the Men's New Roles for Gender Equal Society, funded by the Sasakawa Peace Foundation. The survey was designed and carried out at Intage Co., Ltd. Those responsible for primary data collection bear no responsibility for the analysis and interpretations presented herein. The author also appreciates Elin Kvande for her valuable comments and suggestions.

\section{References}

Aarseth, H. (2020). Against the grain? The craving for domestic femininity in a gender-egalitarian welfare state. The European Journal of Women's Studies, 28(2), 229-243. doi: 10.1177/1350506820970241.

Atoh, M., \& Akachi, M. (2005). Low fertility and family policy in Japan in an international comparative perspective. Journal of Population and Social Security (Population), Supplement to Volume 1, 1-30. Available online at: http:// www.ipss.go.jp/webj-ad/WebJournal.files/population/2003_6/1.Atoh.pdf (accessed 15 December 2020).

Basic Act for Gender-Equal Society. (1999). Gender Equality Bureau Cabinet Office. Available online at: http://www.japaneselawtranslation.go.jp/law/detail_main? $\mathrm{re}=01 \& \mathrm{vm}=04 \& \mathrm{id}=2526$ (accessed 27 March 2020).

Brandth, B., \& Kvande, E. (2003). Fleksible fedre [Flexible fathers]. Universitetsforlaget.

Brandth, B., \& Kvande, E. (2020). Designing parental leave policy: The Norway model and the changing face of fatherhood. Bristol University Press.

Cabinet Office. (2005). Socialization of childrearing [White paper]. Available online at: https://dl.ndl.go.jp/view/download/digidepo_2942973_po_hm020303.pdf? content $\mathrm{No}=23 \&$ alternativeNo $=($ accessed 1 June 2021).

Child Care Leave Law. (1992). Ministry of Health, Labour and Welfare. Available online at http://www.japaneselawtranslation.go.jp/law/detail/?printID= \&id $=3543 \& \mathrm{re}=02 \& v m=04$ (accessed 15 June 2021).

Child Care and Family Care Leave Law. (2010). Ministry of Health, Labour and Welfare. Available online at: https://www.mhlw.go.jp/english/policy/affairs/dl/ 05.pdf (accessed 15 June 2021).

Ellingsæter, A.L. (2020). Conflicting policy feedback: Enduring tensions over father quotas in Norway. Social Politics: International Studies in Gender, State \& Society. doi: $10.1093 / \mathrm{sp} / \mathrm{j} \times \mathrm{aa} 027$.

Elliott, K. (2015). Caring masculinities: Theorizing an emerging concept. Men \& Masculinities, 19, 240-259.

Hayashi, M. (1996). Fusei no fukken [Restoration of paternity]. Chuo Koron Shinsho.

Ishii-Kuntz, M. (2009). Fathers' roles and their childcare involvement. Journal of Household Economy, 81, 16-23.

Ishii-Kuntz, M. (2013). Sociology of child caring men: In search of realizing fathers' involvement in child rearing. Minerva Publications.

Japan Institute for Labour Policy and Training. (2017). Childcare and elder care leave in Europe. Report Series No. 186. 


\section{Masako Ishii-Kuntz}

Kitterød, R.H., \& Kjeldstad, R. (2003). A new father's role? Employment patterns among Norwegian fathers 1991-2001. Economic Survey 1. Statistics Norway.

Lorentzen, J. (2013). The history of fatherhood in Norway, 1850-2012. Palgrave Macmillan.

Ministry of Health, Labour and Welfare. (2017). Hoikusho tou kanren jyoukyou torimatome (Summary of conditions related to day care centres). Available online at: https://www.mhlw.go.jp/stf/houdou/0000176137.html (accessed 19 June 2021).

Ministry of Health, Labour and Welfare. (2020). Koyou kintou kihon chousa no kekka gaiyou. [Basic survey of gender equality in Employment Management]. Available online at: https://www.mhlw.go.jp/toukei/list/d1/71-r01/07.pdf (accessed 20 June 2021).

Ohta, M. (1994). Edo no oyako - chichioya ga kodomo o sodateru jidai [Parents and children in Edo Period: Era of fathers raising children]. Chuo Koronsha.

Osaki, T. (2016). Angry blog post sparks movement for improved day care. The Japan Times. Available online at: www.japantimes.co.jp/news/2016/03/07/national/ angry-blog-post-sparks-movement-for-improved-day-care/\#.WQ7GyBSBi-V (accessed 15 December 2019).

Otoko mo Onna mo Ikujijikan o Renrakukai (Ed.) (1995) Ikuji de kaisha o yasumu yona otoko tachi [Men taking a leave for childcare]. Yukkusha.

Ringrose, P. (2017). Introduction to gender research in Norway [Paper presentation]. IGS International Symposium: Gender Equality in the Happiest Country: Gender Research and Family-Life Balance in Norway, Ochanomizu University, Tokyo, Japan.

Sainsbury, D. (1996). Gender, equality, and welfare states. Cambridge University Press.

Sørensen, S.Ø. (2017). The performativity of choice. Post-feminist perspectives on work-life balance. Gender Work and Organization, 24(3), 297-313.

Tajiri, K. (1990). Tosan wa jitensha ni note - Otoko no ikujijikan suto tenmatsuki [A father riding on a bicycle: A report about a man taking childcare hour strike]. Yukkusha.

Toivonen, T. (2007). Is Japanese family policy turning 'Nordic'? Exposing key challenges for Japan' parental leave and child care schemes. In A. Buchanen, \& M. Seeleib-Kaiser (Eds.), Barnett Papers in Social Research (vol. 1). University of Oxford. Available online at: https://www.spi.ox.ac.uk/sites/default/files/BarnettPaper20071 TuukkaToivonen.pdf (accessed 5 May 2021). 